\title{
LEVANTAMENTO EPIDEMIOLÓGICO DE TRAUMATISMOS ALVÉOLOS DENTÁRIOS DO CENTRO ESPECIALIZADO MARINGAENSE DE TRAUMATISMO
}

Christine Men MARTINS, Adriana Lemos Mori UBALDINI, Mariana Emi NAGATA, João Paulo Guilherme de LIMA, Nair Narumi Orita PAVAN

Com o desenvolvimento da odontologia preventiva, ocorreu notável diminuição da prevalência da cárie dentária. Entretanto, os altos índices de violência, acidentes de trânsitos e atividades esportivas arriscadas contribuíram para transformar o traumatismo dentário em problema de saúde pública. Embora o traumatismo não seja considerado uma doença bucal, ele gera impacto na qualidade de vida, comprometendo a mastigação, fonação, físico e psicológico. O CEMTrau é um projeto de extensão da Universidade Estadual de Maringá que, atendendo toda população, trata pacientes que sofreram traumatismos alvéolos dentários. Objetivouse realizar um levantamento epidemiológico dos pacientes atendidos no CEMTrau no período de 2000 à 2008, onde verificou-se a prevalência do gênero masculino, maior incidência durante a infância, sendo a queda a causa mais comum. O tipo mais freqüente é a fratura coronária sem exposição pulpar seguida da avulsão, e o dente mais afetado, o incisivo central superior. O traumatismo dento-alveolar pode resultar em perdas dentais irreparáveis, tanto no momento do acidente como no decorrer do tratamento ou, até mesmo, anos após. Portanto, o correto diagnóstico, tratamento e acompanhamento são imprescindíveis e o Projeto CEMTrau procura atingir esse objetivo, através de tratamento conservativo e preventivo, além de realizar o controle dos pacientes que sofreram o traumatismo.

Palavras-chave: Epidemiologia; Traumatismo; Traumatismo dentário. 